\title{
FOSFOLIPASAS A2: GRANDES FAMILIAS Y MECANISMOS DE ACCIÓN
}

\author{
Grégory Alfonso García MD, MSc, (c)* , Ananías García Cardona, DDC**
}

\section{Resumen}

Las fosfolipasas A2 (PLA2) constituyen un diverso grupo de enzimas con respecto a secuencia, función, localización y requerimiento por cationes divalentes. Ellas juegan rol importante en una variedad de procesos celulares, incluyendo la digestión y metabolismo de fosfolípidos, así como la producción de precursores para reacciones inflamatorias. Estas enzimas catalizan la hidrólisis de $s n-2$ posición de glicerofosfolípidos membranales para liberar ácido araquidónico (AA), un precursor de eicosanoides. La misma reacción también produce lisofosfolípidos, los cuales representan otra clase de mediadores lipídicos. Además, varios receptores de superficie han sido identificados, como PLA2R1. Revisaremos el conocimiento actual de las propiedades y funciones de este ubicuo y diverso grupo familiar y la evidencia reciente de la actividad fundamental que PLA2 juega en el campo patobiológico.

Palabras clave: bioquímico, enzimología, genética, fosfolipasa AZ (PLA2).

Abreviaturas: PLA2, fosfolipasas A2.

\section{A2 PHOSPHOLIPASES: EXTENDED FAMILIES AND MECHANISMS OF ACTION}

\section{Abstract}

A2 phospholipases (PLA2) constitute a diverse group of enzymes with respect to sequence, function, location and divalent cations. They play an important role in various cell processes, including phospholipid metabolism and digestion, as well as, production of precursors for inflammatory reactions. These enzymes catalyze the hydrolysis of the $s n-2$ position of cell membrane phosphoglycerides to release arachidonic acid (AA) a precursor of eicosanoids. The same reaction also produces lysophospholipids, which represent another class of lipidic mediators. Additionally, several cell surface receptors have been identified as PLA2R1. We will review the present knowledge on the properties and functions of these ubiquitous and diverse family group and the recent evidence of the fundamental activity which PLA2 plays in the pathobiological field.

Key words: biochemical, enzymology, genetics, A2 phospholipase (PLA2).

Fecha recibido: abril 21 de 2009 - Fecha aceptado: agosto 10 de 2009

* Experto Genética, Bioquímica y Biología Celular y Molecular Humana. Docente experto Farmacología y Toxicología Humana. Facultad de Medicina. Unidad de Educación. Unisánitas. Grupo de Medicina Translacional. Instituto de Investigación. Unisánitas. Laboratorio de Inmunología Clínica. Facultad de Ciencias. Pontificia Universidad Javeriana. Bogotá DC, Colombia.

** Docente Coordinador. Unidad de morfología. Facultad de Medicina y Facultad de Terapia, Rehabilitación y Desarrollo Humano. Instituto de Ciencias Básicas, Quinta Mutis. Universidad Colegio Mayor de Nuestra Señora del Rosario. Bogotá DC, Colombia. 


\section{Introducción}

Descritas desde 1967, las fosfolipasas A2 (PLA2) son enzimas del tipo hidrolasa-lipasas, las cuales inducen cambios en la composición membranal, activan la cascada inflamatoria y generan vías de señalamiento celular (transducción de señales). Son responsables de la movilización de ácidos grasos poli-insaturados liberados desde la posición $s n 2$ de los glicerofosfolípidos, lo cual incluye el ácido araquidónico (AA). Están clasificadas en las PLA2 citosólica de alto peso molecular y las PLA2 secretorias de bajo peso molecular. Pertenecen a la familia de las fosfolipasas, superfamilia de las lipasas y megafamilia de las hidrolasas. Previamente los autores y otros colaboradores hicieron una revisión sobre el tema, por lo cual se decidió profundizar sobre ciertas áreas en esta publicación. ${ }^{1}$ En la nomenclatura propuesta por IUBMB (International Union of Biochemistry and Molecular biology), las PLA2 se cobijan bajo la clasificación EC 3.1.1.4. ${ }^{2}$

\section{Metodología}

Para efectuar esta revisión se consultó la literatura científica médica humana, haciendo una búsqueda electrónica en las bases PUBMEDLINE (National Library of Medicine database) y EMBASE (The bibliographic database for biomedical and pharmacological information). Se utilizó la matriz de búsqueda "human phospholipase A2", para los últimos cinco años. Se seleccionaron los artículos pertinenes en la medida en que mostraban importancia biomédica en el tema principal y los subtemas analizados, y además que sus autores fueran reconocidos investigadores de frontera en el campo propuesto para esta revisión.

\section{Esenciales en la diversidad de las PLA2}

Las PLA2 se han podido clasificar por su funcionalidad y localización celular y tisular en dos grandes tipos: citosólicas de alto peso molecular y secretorias de bajo peso molecular. Por su dependencia de calcio en variedades: calcio-dependientes y calcio-independientes. Se utilizan números romanos para los dieciséis (16) gru- pos, es decir, del I al XVI, con diversos subgrupos nominados con letras mayúsculas, comprometiendo la totalidad de enzimas conocidas en acariotas (virus), procariotas (bacterias) y eucariotas (hongos, reptiles y mamíferos). En la Tabla 1 se expone la clasificación grupal de Dennis., ${ }^{3,4}$

La asignación a los distintos grupos depende de los mecanismos catalíticos de las enzimas, lo que ha determinado que la actividad hidrolasa puede ser por la presencia de cualquiera de los tres siguientes mecanismos consistentes en diadas aminoacídicas presentes en los centros catalíticos: histidina/aspartato, serina/aspartato y serina/histidina/aspartato. Los quince grupos a su vez se pueden clasificar grosso modo en cinco tipos principales enzimáticos (Figura 1): 1) enzimas secretorias (sPLA2), 2) enzimas citosólicas (cPLA2), 3) enzimas calcio-independientes (iPLA2) que pueden ser citosólicas, secretorias o mixtas, 4) enzimas degradantes de los mediadores autocoides conocidos como factores activadores plaquetarios (PLA2-PAF-AH), y 5) enzima lisosomal calcio-independiente (L-PLA2), que también posee actividad 1-O-acil-ceramida-sintasa y transacilasa.

En nuestra especie se conocen cinco genes y un pseudogen más, que están relacionados con las PLA2, muchas de las cuales muestran similitud con las iPLA2 y pertenecen a la familia de las patatinas, por cuanto se

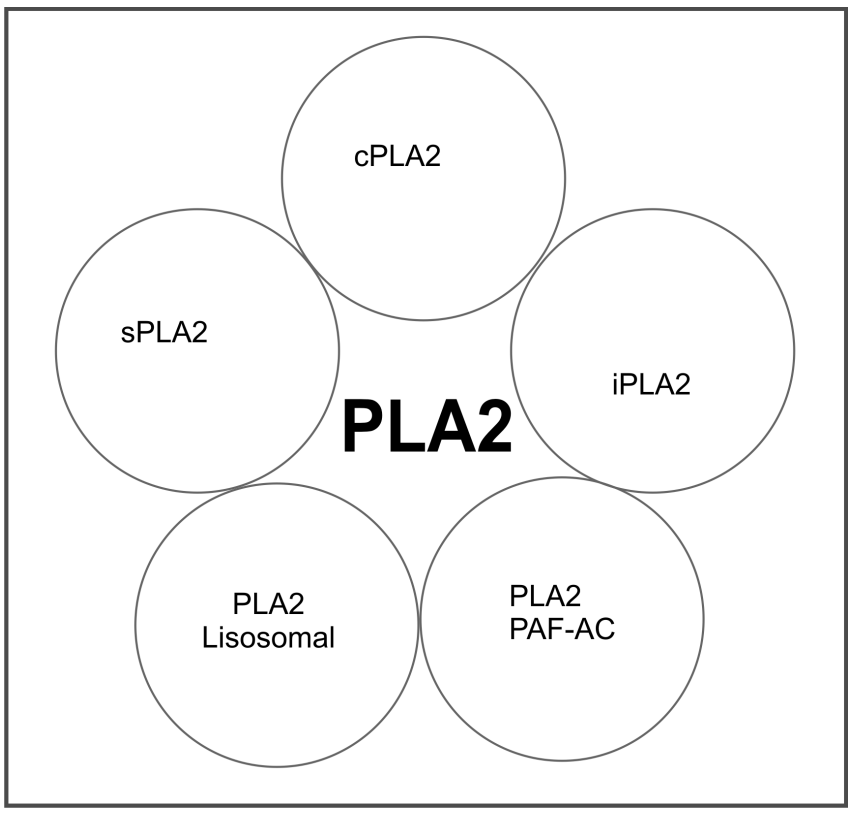

Figura I. Clasificación de las PLA2. 


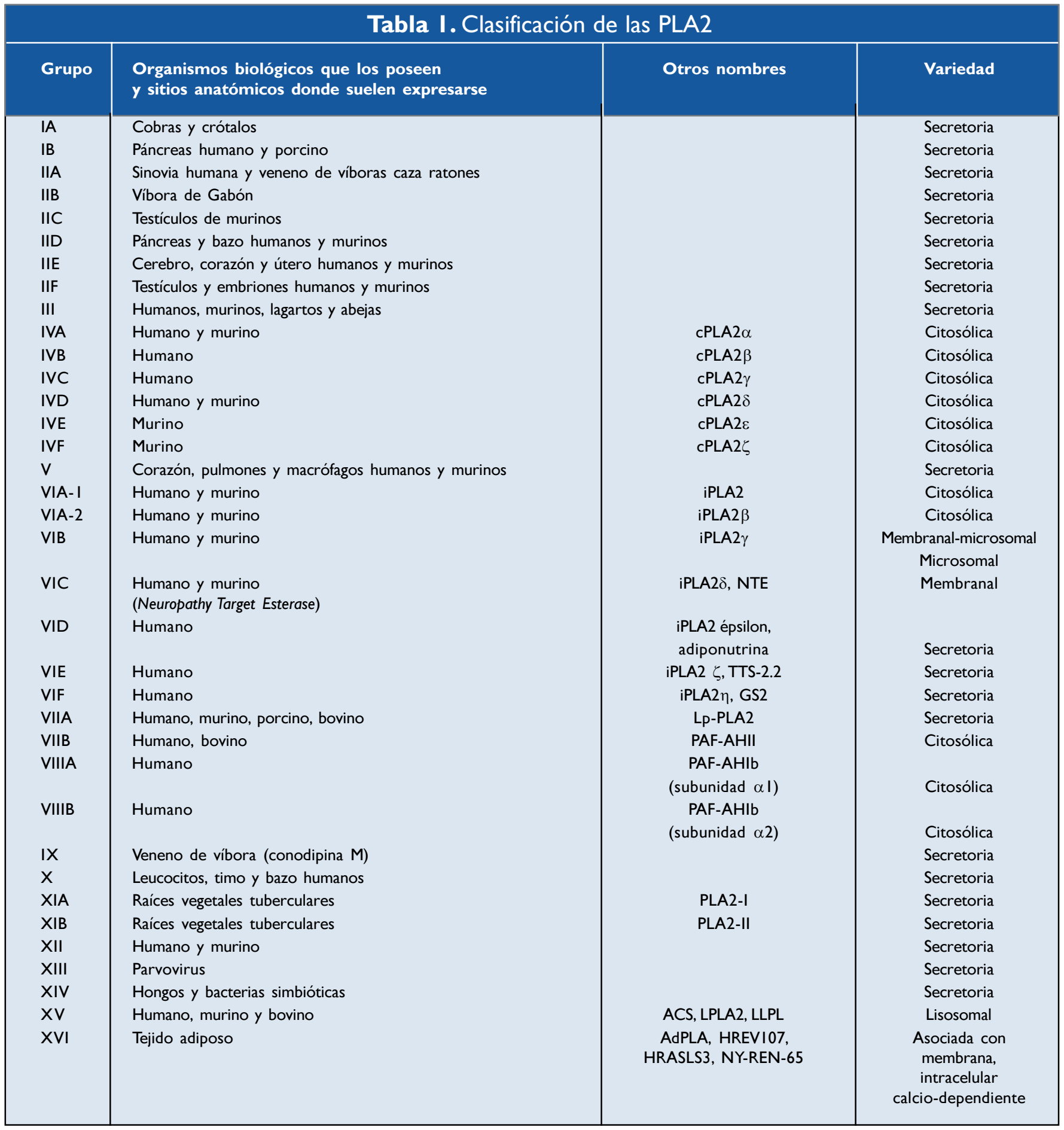

encontraron inicialmente en estos tubérculos. Otras son la otoconin (proteína de la matriz de la otoconias del oído interno) y la PLA2L-HERV (corte y empalme alternativo de un retrovirus endógeno humano). ${ }^{5}$ En esta revisión discutiremos en su orden la información concerniente a la bioquímica estructual y genética de las variedades cPLA2, las iPLA2, las sPLA2 y las PLA2-PAF-AH; el papel de las PLA2 en señalamiento celular, en forma directa como citoquina, sus receptores e indirecta como ruta biosintética de ligandos de señalamiento (lípidos autocoides); y los roles especializados de las SPLA2 y la iPLA2. No tocaremos en esta revisión la temática de la L-PLA2, dado que la información estructural y funcional no está aún aclarada del todo. 


\section{PLA2 citosólicas (cPLA2)}

Muchas de estas enzimas también muestran actividad lisofosfolipasa y transacilasa. Excepto la PLA2G4D que posee una mayor especificidad para clivar ácido linoleico, todas las demás de manera preponderante clivan ácido araquidónico. Estas enzimas son de peso molecular variable entre 61 y 114 kilodalton $(\mathrm{kDa})$ y su centro catalítico utiliza una residuo de serina. La fosforilación de la serina del centro catalítico aumenta la actividad enzimática.

Ellas pertenecen al grupo IV y se distinguen seis subgrupos: IVA, IVB, IVC, IVD, IVE y IVF. Todas excepto la tipo IVC poseen un dominio $\mathrm{C} 2$, que les permite en presencia del calcio ser reclutadas a las membranas celulares, ya que en esta forma reconocen fosfolípidos. La tipo IVC es acilada por medio de farnesilación a la plasmalema, lo cual es consecuente con lo mencionado antes. La presencia del dominio $\mathrm{C} 2$ no sólo les permite ser reclutadas en presencia de calcio, sino que al unir a fosfolípidos membranales les confiere activación. cPLA2 $\alpha$, es decir IVA es regulada por fosforilación, evidenciándose tres sitios claves: a) un residuo de serina (ser505) fosforilado por diversas serina/treonina-kinasas del tipo MAPKs (mitogen-activated protein kinase kinase); b) un residuo serina (ser515) fosforilada por CaMKII (calmodulina kinasa II); y c) un residuo serina (ser727) fosforilado por MNK1 (mitogen-activated protein kinase-interacting serine/threonine kinase 1). ${ }^{6,7}$ cPLA2 $\alpha$ es regulada en forma por la interacción directa con la proteína citoesquelética vimentina, ${ }^{8}$ miembros de la familia proteica $\mathrm{S} 100^{9} \mathrm{y}$ miembros de la familia proteica de las annexinas. ${ }^{10}$ cPLA2 es también en forma positiva regulada por la proteína PLIP (PLA2interacting protein), la cual es una proteína derivada del mismo gen codificante de TIP60/HTATIP(HIV-1 TATinteracting protein, $60-K D)$. TIP60 es una enzima del tipo histona-desacetilasa, es decir, que está involucrada en la regulación de la expresión génica, y una variedad por corte y empalme alternativo de su ARNm (splicing) produce una proteína con actividad reguladora de la actividad de la cPLA2 $\alpha$ (Figura 2). ${ }^{11}$

Aún no hay claridad sobre el papel de los mecanismos de transducción en señales conocidos como "sistemas de proteínas G triméricos", si la activación que se ejercería es directa o indirecta. Los sistemas de proteínas
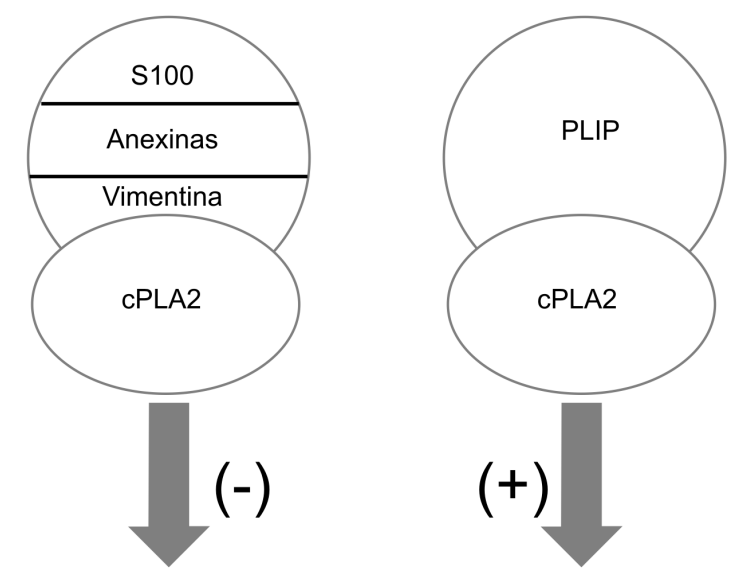

AUTOCOIDES

EICOSANOIDES

Figura 2. Regulación de la cPLA2.

G que poseen las subunidades $\alpha$ Go o Gi (Gi1, Gi2 y Gi3) se acoplan al señalamiento dependiente de fosfolipasas PLC, PLD y PLA2, mientras que las subunidades G12 o G13 se ligan a la activación de las proteínas $\mathrm{G}$ monoméricas de la familia Rho que en forma consuetudinaria activan a las PLD. Este sistema activatorio posee un bucle en el cual las proteínas $\mathrm{G}$ monoméricas Rho activan de manera directa a las MAPK-ERK, las cuales pueden luego fosforilar y activar a las cPLA2. ${ }^{12}$

\section{PLA2 calcio-independientes}

\section{Variedades citosólicas calcio-independientes}

Las variedades citosólicas calcio-independientes pertenecen al grupo VI y se conocen dos miembros y por ende dos genes: la variedad PLA2G6A con cinco tipos distintos por corte y empalme alternativo (splicing) del ARNm y la variedad PLA2G6B con dos tipos distintos de GPVIB por el mismo mecanismo. Lo que caracteriza desde el punto de vista bioquímico a este grupo es la presencia de un tipo muy particular de repeticiones proteicas que se describieron al principio en los miembros de la familia de las anquirinas. Estas secuencias anquirínicas están repetidas en un número variable de siete a ocho veces. Las repeticiones anquirínicas son 
responsables por la formación de oligómeros o de la asociación con otras proteínas que también contengan este tipo de repeticiones. Con respecto a las variantes por corte y empalme alternativo, hay evidencia de que son inhibidores competitivos enzimáticos por oligomerización. El ATP estabiliza la estructura de la PLA2G6A. ${ }^{13,14}$

\section{Otras variedades calcio-independientes}

Las PLA2-VIA es citosólica y las PLA2-VIB y VIC son membranales. Las PLA2-VID, PLA2-VIE y PLA2VIF se han identificado como variedades enzimáticas involucradas en el metabolismo lipoproteico, dada su actividad como acil-glicerol-transacilasas y tri-acil-glicerollipasas. PLA2G6C posee también actividad lisofosfolipasa. Como si fuera poco, es probable que la PLA26D también denominada como adiponutrina y la PLA2G6E denominada como desnutrina, posean actividad hormonal. De ellas, la PLA2G6C muestra además una actividad esterasa detoxificante en el sistema nervioso. ${ }^{15}$

\section{PLA2 secretorias}

Estas PLA2 se encuentran en insectos, moluscos, reptiles, mamíferos, parvovirus, hongos y bacterias simbióticas, y mamíferos. Las variedades secretorias (sPLA2) son proteínas de bajo peso molecular (14$18 \mathrm{kDa}$ ) y estructuralmente contienen de cinco a ocho puentes disulfuro. Su actividad enzimática depende de una diada histidina-aspartato en su centro catalítico y requieren de calcio en concentraciones micromolares. ${ }^{16}$ Las sPLA2 corresponden a los grupos IB, IIA, IIC, IID, IIE, IIF, III, V, X y XII (XIIA y XIIB). Las PLA2 de los grupos sPLA2IIA y sPLA2V poseen una región carboxi-terminal con ámino-ácidos básicos que les permite interactuar con glicosaminoglicanos (GAG) del tipo heparán-sulfato y heparina, presentes en proteinglicanos (PG), en especial PG membranales y en particular los Glypicanes (GPC), de los cuales se conocen seis en nuestra especie: GPC1, GPC2 (también denominado cerebroglycan), GPC3, GPC4 (también denominado K-glypican), GPC5 y GPC6. La interacción con GPC desencadenan cascadas de señalamiento intracelular desde la plasmalema. (Figura 3). ${ }^{17,18}$

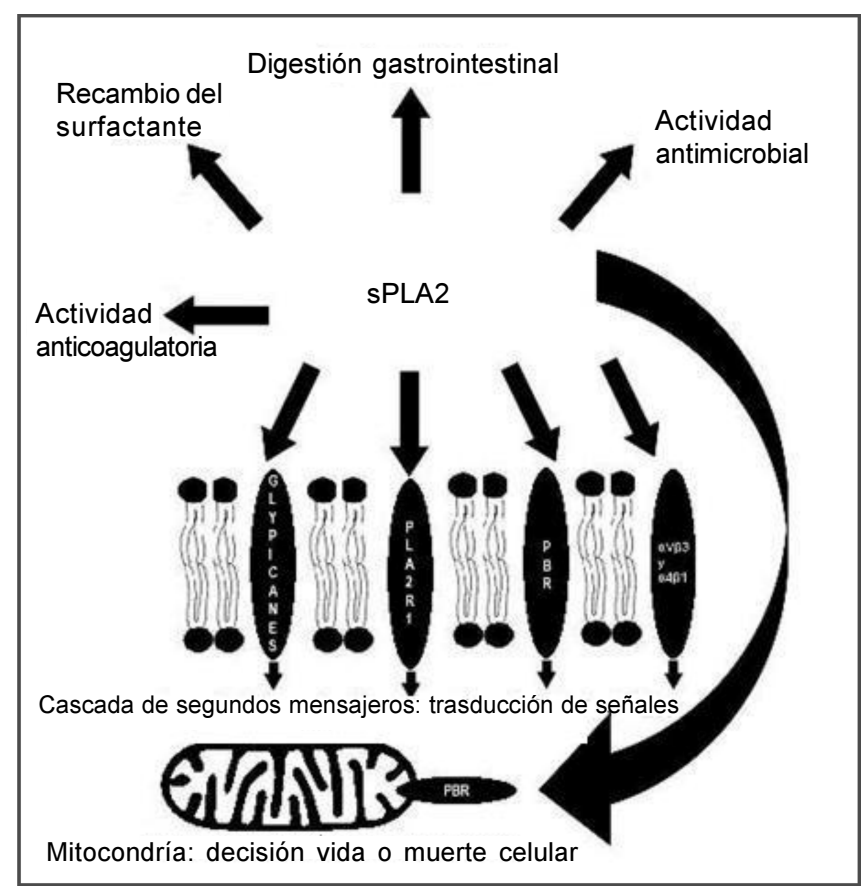

Figura 3. Roles y receptores biológicos para las Spla2.

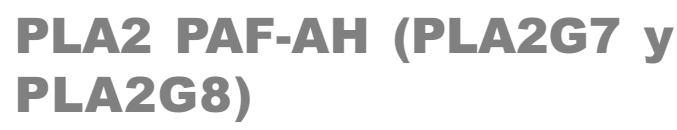

Estas enzimas tienen un núcleo catalítico con una triada serina-histidina-aspartato. Hidroliza ácidos grasos de cadenas corta y mediana a partir de di-acil-gliceroles, tri-acil-gliceroles y fosfolípidos, pero en particular frente a la fosfatidilcolina. También posee una actividad de hidrolasa tipo fosfolipasa A1(PLA1), aunque disminuye en forma proporcional al largo de los ácidos grasos en la posición sn2. Un elemento particular en esta temática es la PLA2G7 secretoria inflamatoria mieloide, conocida clásicamente como la acetil-hidrolasa para los PAF, enzima que es producida por células inflamatorias de origen mieloide y que se caracteriza por estar en estrecha asociación con lipoproteínas plasmáticas y lesiones ateroscleróticas muy vulnerables por ser lesiones de novo. La PLA2G7 degrada tanto los PAFs como ácidos grasos de cadena corta oxidados, a partir de la posición $s n 2$ de los fosfolípidos. Hay evidencia consistente del rol de la PLA2G7B como protector del tipo barredor, de fosfolípidos oxidados y de la PLA2G7A como proinflamatorio al degradar fosfolípidos oxidados en el contexto de lipoproteínas LDL (low density lipoprotein). 
La PLA2G7 cerebral denominada PAF-AHIb o PLA2G8 está constituida por varias subunidades: 1$) \alpha(\mathrm{B} 1)$, por corte y empalme alternativo (splicing) se generan $\alpha 1 \mathrm{y} \alpha 2$, las cuales forman homo o heterodímeros. Los homodímeros $\alpha 1 / \alpha 1$ y $\alpha 2 / \alpha 2$, y el heterodímero $\alpha 1 /$ $\alpha 2$, varían su actividad sobre distintos sustratos de acuerdo con el tipo de dimerización; 2) $\beta(\mathrm{B} 2)$, regulatoria principal;y3) $\gamma(\mathrm{B} 3)$, regulatoria accesoria. De estas subunidades, aún hay discusión cuales son regulatorias y catalíticas. ${ }^{19,20}$

\section{Roles de las PLA2 en comunicación celular}

Es claro que la PLA2 posee dos mecanismos de acción: el directo hace correlación con su actividad enzimática y el indirecto lo hace con su novedosa actividad como un mediador de comunicación celular (MCC).

\section{Mecanismo directo}

La PLA2 puede liberar ácidos grasos insaturados (por lo regular el ácido araquidónico y menor el ácido linoleico) desde fosfolípidos de membrana plasmática, para que éste sea tomado como sustrato para la biosíntesis de autocoides. La afinidad por sustratos varía entre las distintas PLA2, es así que las SPLA2 poseen preferencia catalítica por tres fosfolípidos: fosfatidilglicerol, fosfatidilcolina y fosfatidilserina. Todas las membranas celulares y las de compartimentos subcelulares pueden ser blanco de las PLA2. ${ }^{21,22}$ Existen varias rutas para la biosíntesis de lípidos autocoides eicosanoides, como la de las ciclo-oxigenasa (prostaglandinas, tromboxanos) $^{21,22}$, la ciclo-oxigenasa acetilada por aspirina, que genera lípidos muy especiales denominados como protectinas y resolvinas ${ }^{23,24}$; la de las lipo-oxigenasas (leucotrienos) ${ }^{21,22,23,24,25}$; la biosintética de los endocanabinoides (ej.: anandamida) ${ }^{26}$; la de biosíntesis de los PAFs (factores activadores de plaquetas) ${ }^{27}$; la de los citocromos (ej.: HETEs-ácidos hidroxi-eicosa-tetraenoicos- y EETs-ácidos eicosatetraenoicos) ${ }^{28,29}$; la de los endovaniloides (ej.: araquidonil-dopamina) ${ }^{30} \mathrm{y}$ también por medio de mecanismos anenzimáticos, es decir, en ausencia de enzimas se pueden ciclar los ácidos grasos mediante la oxidación dependiente de radicales libres, donde los produc- tos finales poseen actividades biológicas y se les llama isoprostanos. ${ }^{31}$

Los ácidos grasos libres insaturados per se, pueden actuar por medio de receptores, como los del tipo serpentina asociados con sistemas de proteínas G trimérico GPR ( $G$ protein-coupled receptor) como son GPR40 para ácidos grasos de cadena media, GPR41 para ácidos grasos de cadena corta, GPR43 para ácidos grasos de cadena corta y GPR120 para ácidos grasos de cadena larga. ${ }^{32}$ También los receptores nucleares como los miembros de la familia PPAR (peroxisome proliferator-activated receptor). ${ }^{33}$ La Figura 4 esquematiza la gama biosintética descrita. Estos autocoides poseen infinidad de funciones y el avance bioquímico ha permitido reconocer una pléyade de biomoléculas y actividades, con roles complejos en regulación de los estados sueño-vigilia, respuesta inmune e inflamación, fertilidad, reproducción y nocicepción.

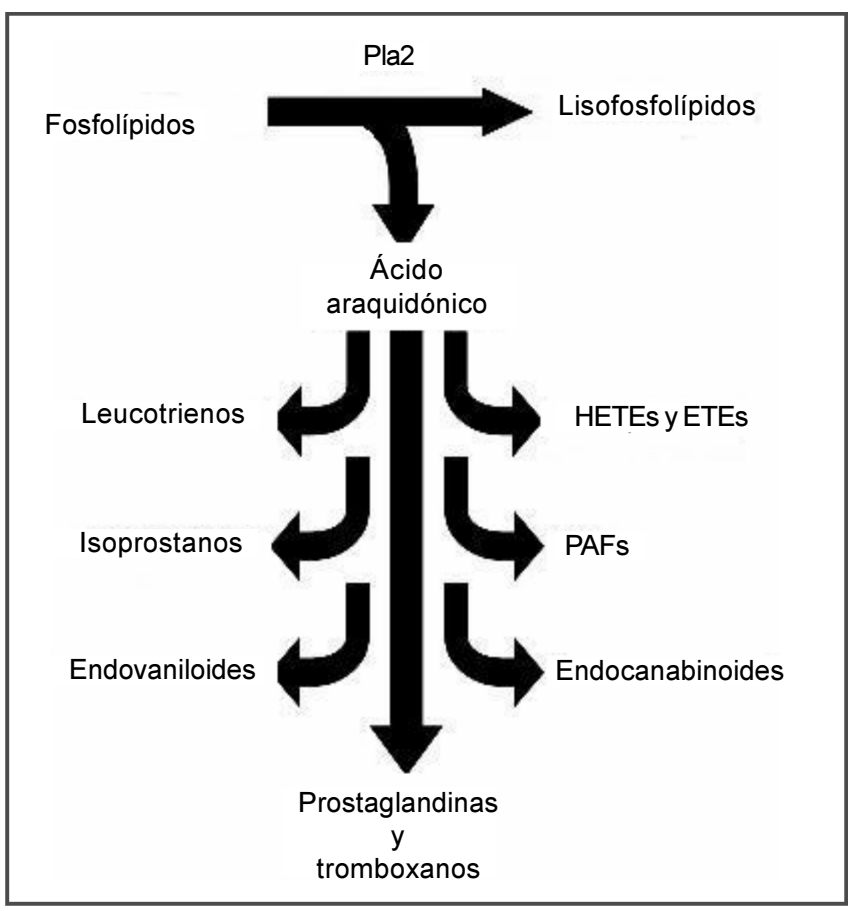

Figura 4. Gama biosintética y diversidad de los eicosanoides.

\section{Mecanismo indirecto: PLA2 como un MCC del tipo citoquina}

El término MCC se refiere a toda sustancia sintetizada por las células de un organismo o una organización 
multicelular con la finalidad de generar comunicación entre sus diversos componentes y en ese orden de ideas favorecer las respuestas orquestadas frente a estímulos de índole endógeno o exógeno, todo ello en veras de producir un proceso de homeostasis, situación que incluye fenómenos como la morfogénesis como la cicatrización y la regeneración. El término MCC equivale al de primer mensajero o ligando. Los MCC son de naturaleza variada si nos referimos a sustancias químicas o por decirlo en forma más adecuada "sustancias bioquímicas", pero no todas son de naturaleza orgánica, es decir, que posean carbono.

Desde hace tiempo se conocen los receptores denominados tipo "N" expresados en las membranas de las células cerebrales en los mamíferos y que median los efectos neurotóxicos de ciertas PLA2, aunque no han sido del todo aislados y clonados. En los últimos años se ha estudiado a fondo el papel del llamado receptor tipo "M", pues miembros de las sPLA2 tienen actividad funcional como MCC actuando a través del receptor membranal específico denominado PLA2R1 (phospholipase A2 receptor 1), que es una proteína de $180 \mathrm{kD}$, transmembranal del tipo I, cuyo gen codificante se encuentra en el cromosoma 2 (locus 2q23-q24). El PLA2R1 es miembro de la familia de las lectinas, proteínas que reconocen carbohidratos libres o en contextos glicolipídicos y/o glicoproteícos. El rastreo genético lo hace pertenecer al subgrupo VI de lectinas, donde comparte familiaridad con miembros como la lectina DEC205 (en nomenclatura de antígenos hemato-inmunes, CD205) y MCR1 (macrophage mannose receptor 1), presente en células presentadoras de antígenos (APC) como las dendríticas.

Existe variable afinidad por el PLA2R1 entre las distintas SPLA2, teniendo alta afinidad las SPLA2 IB, IIA, IIE, IIF, V y X. PLA2R1 tiene funciones accesorias, conclusiones tomadas a partir de que una versión soluble de este receptor se deriva a partir del clivamiento (corte proteolítico) desde la membrana, acción catalizada por metalo-proteinasas, $\mathrm{y}$ otras versiones se derivan a partir del corte y empalme alternativo del ARNm. Estas versiones solubles actúan como inhibidores de las PLA2 mediante el mecanismo de señuelo (decoy), encontrando que la actividad catalítica es menguada. PLA2R1 tie- ne una cascada de señalamiento intracelular donde se han dilucidado componentes como la p38MAPK (mitogen-activated protein kinase), e incluso, lejos de ser curioso y no coincidente, las cPLA2. Esto último en especial cuando el ligando es PLA2G2A y PLA2G10. PLA2R1 también funciona como un receptor de aclaramiento (clearance) para las PLA2, en particular parece ser importante esto dada la expresión en macrófagos reticuloendoteliales. Una amplia variedad de células expresan este receptor, en particular las de linaje hamatoinmune y la gran mayoría de la evidencia muestra un rol activatorio que culmina en proliferación celular, migración, liberación hormonal, producción de mediadores lipídicos y producción citoquínica. Como lo mencionamos antes, proteinglicanos de superficie ricos en heparán-sulfato y heparina, también pueden funcionar como receptores. Reportes recientes muestran que los dímeros integrínicos áVâ3 and á4â1 funcionan como receptores para SPLAIIA en líneas celulares monocíticas. ${ }^{34}$

\section{Otros receptores para SPLA2}

Por último, no se puede olvidar que las PLA2 extracelulares junto con la protoporfirina IX y las 3 endozepinas DBI (diazepam binding inhibitor), TTN (triakontatetraneuropeptide) y ODN (octadecaneuropeptide), son ligandos de los receptores periféricos para benzodiacepinas (PBR). Éstos se clasifican en dos grupos, periféricos PBR (peripheral-type benzodiazepine receptors) y los receptores centrales (CBR), estos últimos corresponden a los del neurotransmisor inhibitorio GABA (ácido $\gamma$-amino butírico). Los PBR son también denominados como "proteína translocadora (TSPO)" de $18 \mathrm{kDa}$. Los PBR son abundantes en el sistema cardiovascular, plaquetas, eritrocitos, linfocitos, células mononucleares fagocíticas, endotelio, músculo estriado esquelético, músculo liso, vascular y mastocitos. Los PBR también se ubican subcelularmente en la mitocondria, donde se acoplan a diversas proteínas tales como IBP (isoquinoline carboxamide binding protein), las proteínas VDAC (voltage-dependent anion channel) VDAC1 y VDAC2, y ANT (adenine nucleotide transporter). El PBR mitocondrial regula tanto los procesos de apoptosis endógena mediada por este organelo, como la biosíntesis esteroidea ${ }^{35}$ (Figura 3). 


\section{Funciones especializadas de las SPLA2 y la IPLA2}

Dejando de lado la actividad ya explicada de la cPLA2 como mecanismo base en la biosíntesis de lípidos autocoides y el rol de la PLA2-PAF-AH como la enzima fuente en la catálisis sintética de los autocoides PAF, sólo nos quedan por discutir los roles especializados de la sPLA2 y la iPLA2, ya que están involucradas gracias a su actividad catalítica en comunicación celular puesto que liberan lípidos autocoides, ${ }^{21,31}$ e inmunidad innata, al funcionar como citotocinas frente a las membranas celulares de agentes patógenos o células neoplásicas, como algunas formas secretorias producidas por las células de Paneth del intestino que poseen actividad microbicida. ${ }^{36,37}$ Se ha encontrado que son antibacteriales las PLA2G2A, PLA2G5, PLA2G10 y PLA2G12 ${ }^{38,39}$, antifúngica la PLA2G5, ${ }^{40,41}$ antivirales las PLA2G5 y PLA2G1042 y antirretroviral contra el HIV1, la PLA2G10. ${ }^{43}$ Esta actividad se atribuye en principio a su propiedad fosfolipasa y a su rol como citotoxina del tipo perforina. Se espera el hallazgo de otros mecanismos directos e indirectos. Fertilidad, por cuanto su detección ha sido determinada en el epitelio germinador seminífero, en los espermatozoides maduros y en la próstata (en especial en el lóbulo posterior y glándulas parauretrales). La actividad de la PLA2G7 es detectable en el semen humano y esta enzima es un factor candidato para decapitación espermática, mientras que sus sustratos PAFs (factores activadores plaquetarios) son cualificados como candidatos para capacitación espermática. Así mismo, el acrosoma espermático posee diversas enzimas lisosomales y entre ellas una PLA2 no caracterizada aún, la cual degrada el 1-palmitoil-2docosahexaenoil-sn-glicero-3-fosfocolina (PDPC), el cual es el principal fosfolípido del espermalema. ${ }^{44}$ Los autocoides eicosanoides denominados como endocanabinoides (ver adelante) son claves en el proceso de implantación placentaria. ${ }^{45}$ Continuando con similares temáticas, las PLA2G2A y PLA2G4A juegan un rol en la consecusión del parto. ${ }^{46}$ Permeabilidad cutánea, dado que las sPLA2 degradan lípidos polares en los estratos más exteriores epidérmicos, generando ácidos grasos, los cuales en conjunción con la ceramida, son los mayores impermeabilizadores del estrato córneo y disyuntivo. ${ }^{47,48}$ Digestión gastrointestinal: la
PLA2G1B es un producto exocrino del jugo pancreático. ${ }^{49}$ Recambio del surfactante alveolar por parte de la PLA2G2A. ${ }^{50}$ Actividad anticoagulatoria, ya que PLA2G2A, PLA2G2D y PLA2G5 inhiben la actividad protrombinasa a través de su unión con el factor Xa (factor X activado). Este fenómeno parece ser un retrocontrol negativo fisiológico, si partimos del hecho de que normalmente muchos lípidos autocoides son procoagulatorios trombógenos. Un proceso similar es el que explica el rol patofisiológico de las PLA2 presentes en venenos de víboras. ${ }^{51,52}$

Las iPLA2 calcio-independientes intervienen en el remodelamiento membranal, dado que participan en forma activa en el mantenimiento y reciclaje de fosfolipídicos, en particular las iPLA2 y PLA2G7B. Esta última incluso parece ser un mecanismo importante en el barrido de fosfolípidos oxidados en piel. ${ }^{15,53,54} \mathrm{Co}$ municación y señalamiento celular, ya que está involucrada en la ruta de salvamento de calcio, la cual consiste en que cuando hay disminución franca de las concentraciones de calcio a nivel intracelular, se activa el flujo plasmalémico a través de canales y bombas de influjo, ruta denominada SOC (store-operated channels), y donde sobresale el papel de un complejo ternario de membrana constituido por las proteínas Orai1, STIM1 y TRPC1. 15,55,56,57,58 Apoptosis, debido a que una variante de la PLA2VIA es clivada por enzimas de muerte celular como las CASPASAS (aspartate-specific cysteine protease), tras lo cual son activadas y participan en el empacado de cuerpos apoptóticos. Además, ya en la superficie de los cuerpos apoptóticos actúa sobre los fosfolípidos y se liberan en forma secundaria mediadores lipídicos autocoides que promueven una respuesta inmune tolerante, mediante la biosíntesis de PGE2 y lipoxinas. ${ }^{15,59}$ Una variedad enzimática específica de PLA2VIB se encuentra en los peroxisomas, y podría estar involucrada en diversos procesos del metabolismo de lípidos en órganos como el hígado. ${ }^{15,60}$ La PLA2G6C es una enzima axonal implicada en la detoxificación de compuestos organofosforados. ${ }^{61}$ Las iPLA2 calcio-dependientes implicadas en particular en señalamiento intracelular son importantes en la regulación del metabolismo lipídico, como sucede con la adiponutrina y la desnutrina $^{15,62,63}$ (Figura 5). 


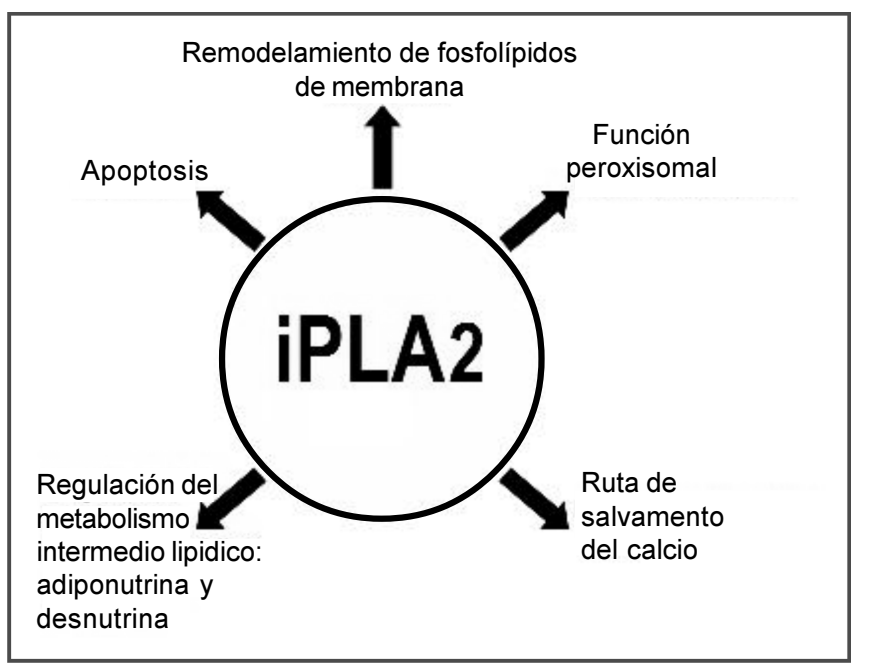

Figura 5. Roles biológico de la ipla2.

\section{Conclusión}

La temática y la problemática de las PLA2 ha avanzado de manera vertiginosa en las áreas de las ciencias naturales y es necesaria una aproximación a su biología, bioquímica, genética y patobiología para conocer los diversos fenómenos fisiológicos y patológicos. Es un amplio campo en plena expansión y con esperanzadores mecanismos farmacológicos y terapeúticos.

\section{Referencias}

1. García GA, Gaitán AA, García Cardona A, Clavijo D, Mejía ÓR, Cobos Claudia et al. Aspectos biomédicos de las fosfolipasas A2 en la especie humana. Med UNAB. 2008; 11(1): 14-27.

2. IUPAC, IUBMB, [BASE DE DATOS EN INTERNET]. LONDON: INTERNATIONAL UNION OF BIOCHEMISTRY AND MOLECULAR BIOLOGY; 1977, [FECHA DE ACCESO 20 DE ABRIL DEL 2009]. DISPONIBLE EN: http:// www.chem.qmul.ac.uk/iupac/jcbn/index.html\#2.

3. OMIM [base de datos en Internet]. Baltimore: Johns Hopkins University; 1966, [fecha de acceso 20 de abril del 2009]. Disponible en: http://www.ncbi.nlm.nih.gov/entrez/dispomim.

4. HUGO [base de datos en Internet]. Bethesda: National Library of Medicine and others (exp.: Celera Genomics and the Sanger Center); 1989, [fecha de acceso 20 de abril del 2009]. Disponible en: http:/ /www.hugo-international.org/index.html.

5. Schaloske RH, Dennis EA. The phospholipase A2 superfamily and its group numbering system. Biochim Biophys Acta. 2006; 1761(11): 1246-59.
6. Ghosh M, Tucker DE, Burchett SA, Leslie CC. Properties of the Group IV phospholipase A2 family. Prog Lipid Res. 2006; 45(6): 487-10.

7. Shimizu T, Ohto T, Kita Y. Cytosolic phospholipase A2: biochemical properties and physiological roles. IUBMB Life. 2006; 58(5-6): 328-33.

8. Grewal S, Herbert SP, Ponnambalam S, Walker JH. Cytosolic phospholipase A2-alpha and cyclooxygenase-2 localize to intracellular membranes of EA.hy.926 endothelial cells that are distinct from the endoplasmic reticulum and the Golgi apparatus. FEBS J. 2005; 272(5): 1278-90.

9. Bailleux A, Wendum D, Audubert F, Jouniaux AM, Koumanov K, Trugnan $\mathrm{G}$ et al. Cytosolic phospholipase A2-p11 interaction controls arachidonic acid release as a function of epithelial cell confluence. Biochem J. 2004; 378(Pt 2): 307-15.

10. Parente L, Solito E. Annexin 1: more than an anti-phospholipase protein. Inflamm Res. 2004; 53(4): 125-32.

11. Sheridan AM, Force T, Yoon HJ, O'Leary E, Choukroun G, Taheri MR et al. PLIP, a novel splice variant of Tip60, interacts with group IV cytosolic phospholipase A(2), induces apoptosis, and potentiates prostaglandin production. Mol Cell Biol. 2001; 21(14): 4470-81.

12. Mariggiò S, Bavec A, Natale E, Zizza P, Salmona M, Corda D et al. Galpha13 mediates activation of the cytosolic phospholipase A2alpha through fine regulation of ERK phosphorylation. Cell Signal. 2006; 18(12): 2200-08.

13. Mosavi LK, Cammett TJ, Desrosiers DC, Peng ZY. The ankyrin repeat as molecular architecture for protein recognition. Protein Sci. 2004; 13(6): 1435-48.

14. Li J, Mahajan A, Tsai MD. Ankyrin repeat: a unique motif mediating protein-protein interactions. Biochemistry. 2006; 45(51): 15168-78.

15. Akiba S, Sato T. Cellular function of calcium-independent phospholipase A2. Biol Pharm Bull. 2004; 27(8): 1174-78.

16. Murakami M, Kudo I. Secretory phospholipase A2. Biol Pharm Bull. 2004; 27(8): 1158-1164.

17. Fransson LA. Glypicans. Int J Biochem Cell Biol. 2003; 35(2): 125-29.

18. Fransson LA, Belting M, Cheng F, Jönsson M, Mani K, Sandgren S. Novel aspects of glypican glycobiology. Cell Mol Life Sci. 2004; 61(6): 1016-24.

19. Arai H. Platelet-activating factor acetylhydrolase. Prostaglandins Other Lipid Mediat. 2002; 68-69: 83-94.

20. Karasawa K, Harada A, Satoh N, Inoue K, Setaka M. Plasma platelet activating factor-acetylhydrolase (PAF-AH). Prog Lipid Res. 2003; 42(2): 93-14.

21. Cook JA. Eicosanoids. Crit Care Med. 2005; 33(12 Suppl): S488-91.

22. Khanapure SP, Garvey DS, Janero DR, Letts LG. Eicosanoids in inflammation: biosynthesis, pharmacology, and therapeutic frontiers. Curr Top Med Chem. 2007; 7(3): 311-40.

23. Chiang N, Serhan CN. Cell-cell interaction in the transcellular biosynthesis of novel omega-3-derived lipid mediators. Methods Mol Biol. 2006; 341: 227-50. 
24. Serhan CN. Novel chemical mediators in the resolution of inflammation: resolvins and protectins. Anesthesiol Clin. 2006; 24(2): 341-64.

25. Kuhn H, O'Donnell VB. Inflammation and immune regulation by 12/15-lipoxygenases. Prog Lipid Res. 2006; 45(4): 334-56.

26. Smita K, Sushil Kumar V, Premendran JS. Anandamide: an update. Fundam Clin Pharmacol 2007; 21(1): 1-8.

27. Stafforini DM, McIntyre TM, Zimmerman, GA Prescott SM. Platelet-activating factor, a pleiotrophic mediator of physiological and pathological processes. Crit Rev Clin Lab Sci. 2003; 40(6): 643-72.

28. Spector AA, Fang X, Snyder GD, Weintraub NL. Epoxyeicosatrienoic acids (EETs): metabolism and biochemical function. Prog Lipid Res. 2004; 43(1): 55-90.

29. Elbekai RH, El-Kadi AO. Cytochrome P450 enzymes: central players in cardiovascular health and disease. Pharmacol Ther. 2006; 112(2): 564-87.

30. Van Der Stelt M, Di Marzo V. Endovanilloids. Putative endogenous ligands of transient receptor potential vanilloid 1 channels. Eur J Biochem. 2004; 271(10): 1827-34.

31. Montuschi P, Barnes P, Roberts LJ 2nd. Insights into oxidative stress: the isoprostanes. Curr Med Chem. 2007; 14(6): 703-17.

32. Milligan G, Stoddart LA, Brown AJ. G protein-coupled receptors for free fatty acids. Cell Signal. 2006; 18(9): 1360-65.

33. Kostadinova R, Wahli W, Michalik L. PPARs in diseases: control mechanisms of inflammation. Curr Med Chem. 2005; 12(25): 2995-09.

34. Burke JE, Dennis EA. Phospholipase A2 biochemistry. Cardiovasc Drugs Ther. 2009; 23(1): 49-59.

35. Veenman L, Gavish M. The peripheral-type benzodiazepine receptor and the cardiovascular system. Implications for drug development. Pharmacol Ther. 2006; 110(3): 503-24.

36. Muller CA, Autenrieth IB, Peschel A. Innate defenses of the intestinal epithelial barrier. Cell Mol Life Sci. 2005; 62(12): 1297. 1307.

37. Keshav S. Paneth cells: leukocyte-like mediators of innate immunity in the intestine. J Leukoc Biol. 2006; 80(3): 500-08.

38. Beers SA, Buckland AG, Koduri RS, Cho W, Gelb MH, Wilton DC. The antibacterial properties of secreted phospholipases A2: a major physiological role for the group IIA enzyme that depends on the very high $\mathrm{pI}$ of the enzyme to allow penetration of the bacterial cell wall. J Biol Chem. 2002; 277(3): 1788-93.

39. Nevalainen TJ, Graham GG, Scott KF. Antibacterial actions of secreted phospholipases A2. Biochim Biophys Acta. 2008; 1781(12): $1-9$.

40. Diaz BL, Satake Y, Kikawada E, Balestrieri B, Arm JP. Group V secretory phospholipase A2 amplifies the induction of cyclooxygenase 2 and delayed prostaglandin $\mathrm{D} 2$ generation in mouse bone marrow culture-derived mast cells in a strain-dependent manner. Biochim Biophys Acta. 2006; 1761(12): 1489-97.

41. Satake Y, Diaz BL, Balestrieri B, Lam BK, Kanaoka Y, Grusby MJ et al. Role of group $\mathrm{V}$ phospholipase $\mathrm{A} 2$ in zymosan-induced eicosanoid generation and vascular permeability revealed by targeted gene disruption. J Biol Chem. 2004; 279(16): 16488-94.

42. Mitsuishi M, Masuda S, Kudo I, Murakami M. Group V and X secretory phospholipase A2 prevents adenoviral infection in mammalian cells. Biochem J. 2006; 393(Pt1): 97-106.

43. Kim JO, Chakrabarti BK, Guha-Niyogi A, Louder MK, Mascola JR, Ganesh L, et al. Lysis of human immunodeficiency virus type 1 by a specific secreted human phospholipase A2. J Virol. 2007; 810028(3): 1444-50.

44. Zhu J, Massey JB, Mitchell-Leef D, Elsner CW, Kort HI, Roudebush WE. Platelet-activating factor acetylhydrolase activity affects sperm motility and serves as a decapacitation factor. Fertil Steril. 2006; 85(2): 391-94.

45. Wang H, Xie H, Dey SK. Endocannabinoid signaling directs periimplantation events. AAPS J. 2006(2); 8: E425-432.

46. Lappas M, Rice GE. Phospholipase A2 isozymes in pregnancy and parturition. Prostaglandins Leukot Essent Fatty Acids. 2004; 70(2): 87-100.

47. Burke JR. Targeting phospholipase A2 for the treatment of inflammatory skin diseases. Curr Opin Investig Drugs. 2001; 2(11): $1549-1552$

48. Maury E, Julié S, Charvéron M, Gall Y, Chap H. Lipids and skin inflammation: role of phospholipases A2. Pathol Biol (Paris). 2003; 51(5): 248-52

49. Whitcomb DC, Lowe ME. Human pancreatic digestive enzymes. Dig Dis Sci 2007; 52(1): 1-17.

50. Touqui L, Wu YZ. Interaction of secreted phospholipase A2 and pulmonary surfactant and its pathophysiological relevance in acute respiratory distress syndrome. Acta Pharmacol Sin 2003; 24(12): 1292-96.

51. Mounier CM, Bon C, Kini RM. Anticoagulant venom and mammalian secreted phospholipases $A(2)$ : protein- versus phospholipid-dependent mechanism of action. Haemostasis. 2001; 31(3-6): 279-87

52. Kini RM. Anticoagulant proteins from snake venoms: structure, function and mechanism. Biochem J. 2006; 397: 377-87.

53. Matsuzawa A, Hattori K, Aoki J, Arai H, Inoue K. Protection against oxidative stress-induced cell death by intracellular plateletactivating factor-acetylhydrolase II. J Biol Chem. 1997; 272(51): 32315-20.

54. Marques M, Pei Y, Southall MD, Johnston JM, Arai H, Aoki J, et al. Identification of platelet-activating factor acetylhydrolase II in human skin. J Invest Dermatol. 2002; 119: 913-9.

55. Smani T, Zakharov SI, Leno E, Csutora P, Trepakova ES, Bolotina VM. Ca2+-independent phospholipase A2 is a novel determinant of store-operated Ca2+ entry. J Biol Chem. 2003; 278(14): 1190915 .

56. Smani T, Zakharov SI, Csutora P, Leno E, Trepakova ES, Bolotina VM. A novel mechanism for the store-operated calcium influx pathway. Nat Cell Biol. 2004; 6: 113-20.

57. Bolotina VM, Csutora P. CIF and other mysteries of the storeoperated Ca2+-entry pathway. Trends Biochem Sci. 2005; 30: 378-87. 
58. Cheng KT, Liu X, Ong HL, Ambudkar IS. Functional requirement for Orai1 in store-operated TRPC1-STIM1 channels. J Biol Chem. 2008; 283(19): 12935-40.

59. Balsinde J, Balboa MA. Cellular regulation and proposed biological functions of group VIA calcium-independent phospholipase A2 in activated cells. Cell Signal. 2005; 17: 1052-62.

60. Yang J, Han X, Gross RW. Identification of hepatic peroxisomal phospholipase $\mathrm{A}(2)$ and characterization of arachidonic acidcontaining choline glycerophospholipids in hepatic peroxisomes. FEBS Lett. 2003; 546: 247-50.
61. Peterson B, Knotts T, Cummings BS. Involvement of Ca2+independent phospholipase $\mathrm{A} 2$ isoforms in oxidant-induced neural cell death. Neurotoxicology. 2007; 28: 150-60.

62. Duncan RE, Ahmadian M, Jaworski K, Sarkadi-Nagy E, Sul HS. Regulation of lipolysis in adipocytes. Annu Rev Nutr. 2007; 27: 79-101.

63. Jaworski K, Sarkadi-Nagy E, Duncan RE, Ahmadian M, Sul HS. Regulation of triglyceride metabolism. IV. Hormonal regulation of lipolysis in adipose tissue. Am J Physiol Gastrointest Liver Physiol. 2007; 293: G1-4. 